\title{
New Approach in Assessing Cement Mortar Remains on Recycled Aggregate
}

\author{
Vivian W. Y. $\operatorname{Tam}^{1} *$ and C. M. Tam ${ }^{2}$
}

\begin{abstract}
There is a growing concern on environmental impacts resulted from construction activities. Accordingly, there is a pressing need on the adoption of recycled aggregate in Hong Kong. One of the key quality yardsticks in assessing the performance of recycled aggregate is the quantity of cement mortar remained on the surface of the aggregate. There have been a number of methods designed to assess the mortar remains indirectly such as densities, water absorption rates, ten percent fine values, etc. This paper proposes a new method to assess the cement mortar remains and categorize the recycled aggregate using a classification system called CSAggregate with a CSAggregate index ranging from zero to one hundred. Ten samples of recycled aggregate collected from ten demolition sites and one ordinary aggregate were examined and compared. The reliability of the classification system was verified by correlating the index to water absorption rates and densities of aggregate.
\end{abstract}

Keywords: Classification system, cement portion remains, density, water absorption, recycled aggregate

\footnotetext{
${ }^{1 *}$ Corresponding author, Lecturer, Griffith School of Engineering, Gold Coast Campus, Griffith University PMB50 Gold Coast Mail Centre, Qld 9726, Australia. Email: v.tam@griffith.edu.au.

${ }^{2}$ Professor, Department of Building \& Construction, City University of Hong Kong, 83 Tat Chee Avenue, Kowloon, Hong Kong.
} 


\section{Introduction}

Under the strong public objection to land reclamation, exhaustion of public landfill areas and the continuous generation of thousands of tons of construction and demolition (C\&D) waste, Hong Kong is stressed in trying to reduce waste generation and to develop new recycling technology. Although recycling of $C \& D$ waste has been advocated for years, implementation of waste recycling in Hong Kong is lagging behind other developed countries due to: first, the comparatively low environmental awareness of construction practitioners and second, the lack of technical know-how.

In considering waste recycling, three major issues need to be taken into account ${ }^{1}$ : i) economy; ii) compatibility with other materials; and iii) material properties. From purely the economic point of view, recycling of $C \& D$ waste is only attractive when the recycled product is competitive with natural resources in relation to cost and quality; for example, in regions where a shortage of both raw materials and landfill sites exists.

To facilitate the use of recycled aggregate (RA), the Civil Engineering Department of the Hong Kong Special Administrative Region (HKSAR) has set up a recycling plant to produce recycled aggregate in Tuen Mun Area 38; the Buildings Department has issued a practice note on "Use of Recycled Aggregates in Concrete”; and the Environment, Transport and Works Bureau has published a Technical Circular (Ref: 12/2002) entitled "Specifications Facilitating the Use of Recycled Aggregates” while the Architectural Services Department of HKSAR has been examining the possibility of using twenty percent of recycled aggregate for building project development; all aims at promoting the use of recycled aggregate, setting standards and practice 
guidelines for RA.

Although there are many standards and guidelines worldwide in relation to the production and application of recycled aggregate, a definitive classification system for recycled aggregate is lacking. Unlike ordinary aggregate, recycled aggregate is coated with patches of cement paste remains that increase water absorption, prolong the required mixing time and affect the mechanical properties of recycled aggregate concrete. Standards for assessing the properties of aggregate are mainly designed for new ordinary aggregate but not for recycled aggregate; for example, the standards of British Standard Institution were designed for ordinary aggregate only.

\section{Significance of the Study}

This paper attempts to explore the following issues: (i) analyzing the current classification systems; (ii) explaining the importance in measuring the amount of cement paste remains on recycled aggregate; iii) developing new methods in categorizing recycled aggregate by measuring the cement paste remains, named as CSAggregate; and iv) assessing the reliability of the new approach by correlating the results to water absorption rates and densities of RA.

\section{Current Classification System for Aggregate}

There are a number of methods adopted to classify recycled aggregate worldwide, including measuring the density, water absorption, chloride contents, sulphate contents, foreign materials, qualification of grain-size, maximum percentage of fine particles, ten percent fine values and particle shape. The details are as follows: 
(a) Density is the most fundamental classification parameter. Lower density of recycled aggregate is due to the existence of porous and less dense residual mortar lumps or particles adhering to the surface of original aggregate particles. Measured aggregate density constitutes a very important parameter for accurate batching and concrete mix design, which is influenced by variations in the composition of the recycled materials. Normally, the classification will accord various ranges of density between 2,100, 1,600 and $1,000 \mathrm{~kg} / \mathrm{m}^{3}$ [2-5]. Aggregate with density lower than $1,000 \mathrm{~kg} / \mathrm{m}^{3}$ will normally not recyclable.

(b) Water absorption is also one of the key performance indicators for RA. It is the most commonly determined using the twenty-four hour measurement approach but ten minute measurement is also adopted in Germany [3]. In general, the RA absorption rates are highly variable and generally higher than the standard threshold for normal aggregate. Higher absorption rates pose potential problems for concrete production given that water demand and concrete workability can be severely altered. RA with higher than fifteen percent in water absorption will not be adopted in many countries [2, 4-6]. Pre-wetted RA normally offsets inadequate concrete workability that results from possible variations in water absorption rates [2, 4].

(c) Chloride content, derived from marine structures or similarly exposed structural elements, can induce corrosion of steel reinforcements. Depending on the source of aggregate, chloride may be present in aggregate, either as potassium or sodium salts. A limit on total chloride content of aggregate is required to minimize the risk of embedded steel reinforcement corrosion and about $0.05 \%$ is the most commonly adopted limit for many countries [2, 4-5]. 
(d) Sulphate content may give rise to expansive disruption of concrete. Some types of sulphates in RA present as cement hydrates in the hardened concrete or residual mortar that may be less likely to participate in any further reaction with the new concrete. Other sulphur compounds present in RA may oxidise in the concrete to produce sulphates under appropriate conditions leading to deleterious expansive reactions. Less than one percent of sulphate content is always limited in various applications [2, 4-5].

(e) Foreign materials, include asphalt, plaster, metal, glass, bitumen, clay lumps, tar, stony material, soft material and degradable organic contaminants. The extent to which foreign materials are likely to adversely affect concrete properties can be assessed through suitable leaching or related test methods. Fine aggregate is generally more susceptible to such contaminants than the coarse fraction. The typical effect on hardened concrete properties is volume instability, setting and hardening behaviour. Therefore, less than one percent of foreign materials should be limited [2-5].

(f) Qualification of Grain-size: grain size distribution of RA is required to be same as that of the normal aggregate. Since the grain-size qualification plays a significant role in influencing the concrete properties, including drying shrinkage of concrete, workability of concrete and also the production cost $^{7}$; therefore, a suitable grading of aggregate should be stipulated according to British Standard (BS) 882 [2, 4, 8].

(g) Maximum percentages of fine particles: the fine particles will directly affect the concrete performance, particularly on the strength and workability; therefore, it should be controlled to be within four percent [2, 4]. 
(h) Ten percent fine value reflects the strength performance of aggregate. A minimum of $100 \mathrm{kN}$ is required for RA, even for both minor structural or non-structural applications in Hong Kong [2].

(i) Particle shape: different crushing processes can affect the results of aggregate on particle shape, which will affect the behavior of aggregate and concrete. However, the requirement of particle shape on recycled aggregate is the same as normal aggregate of maximum of about $40 \%$ [2].

\section{Importance of Cement Paste Remains on Aggregate}

The major difference between recycled aggregate and ordinary aggregate is the amount of cement mortar attached on the aggregate. When old concrete is crushed, a certain amount of mortar from the original cement mortar remains attached to the stone particles in the RA [9]. The porosity of cement mortar remains directly influences the properties of the aggregate [10]; for examples, lower strength, higher water absorption and lower density. Therefore, estimation of the cement mortar remains is the best method to assess the quality of RA, which can then be classified for different applications without influencing the ultimate behaviour of recycled aggregate concrete.

\section{Classification System on Cement Portion Remains: CSAggregate}

As described above, there are a number of methods for understood the quality of recycled aggregate including density, water absorption, ten percent fine values, etc. However, most of these tests are time consuming to prepare with complicated operational procedure. Further, as these methods such as water absorption and density can only help measure the cement mortar 
remains indirectly, interpretation of the results needs to be executed with care. Hence, a clearer, more direct and easily apprehensible classification system needs to be developed. This paper introduces a standard Classification System on Cement Portion Remains, named as CSAggregate.

CSAggregate adopts a more direct way in measuring the cement paste remains. First, two kilogram of aggregate (sizes can be ranging from 5 to 40mm) is sampled and placed in a mixer (see Figure 1) with a diameter of $40 \mathrm{~cm}$ and stirred for one minute. Sieve analyses are used to assess the distribution of particle sizes both before and after mixing. The percentage of particles retained in each sieve ' $i$ ' are measured and the difference in percentages between before and after mixing $\left(P_{i, a}-P_{i, b}\right)$ are derived with sizes of sieve defined in British Standard (BS) 882 [8]. During stirring, the weaker or loosely attached cement pastes will flake off. Therefore, the higher the percentage difference $\left(P_{i, a}-P_{i, b}\right)$ for each sieve $i$ collected in the CSAggregate, the worse the quality of the aggregate will be. CSAggregate provides a reference value: CSAggregate Index which can be derived from Equation (1), ranging from zero to one hundred. A value of "zero" means the RA having zero percent of cement portion flaking off while a higher value stands for higher percentage of cement portion flaking off. The index represents the ratio of the area enclosed by the sieve analysis curves for the sampled RA before and after mixing over the area of the sieve analysis curve before mixing:

$$
\frac{\sum_{i=1}^{n}\left[\left(P_{i, a}-P_{i, b}\right)+\left(P_{i-1, a}-P_{i-1, b}\right)\right]\left(S_{i}-S_{i-1}\right)}{\sum_{i=1}^{n}\left(P_{i, b}+P_{i-1, b}\right)\left(S_{i}-S_{i-1}\right)} \times 100 \%
$$

where $P_{i, a}$ is the aggregate retained in sieve $i$ after stirring in \%; $P_{i, b}$ the aggregate retained in sieve $i$ before stirring in \%; and $S_{i}$ the size of sieve $i$ in $\mathrm{mm}$.

$<$ Figure $1>$ 


\section{Evaluation of CSAggregate}

To evaluate CSAggregate, ten samples of RA were obtained from ten demolition sites with service lives ranging from ten to forty years (see Figure 2). They were compared with the results of the ordinary aggregate sample (Sample 11).

$<$ Figure 2>

First, 20mm RA from the demolition sites was studied. The results on the eleven samples are tabulated in Table 1. The shaded area enclosed by the sieve analysis curves for the RA sample before and after stirring shown in Figure 3 to Figure 12 represents the cement portion flaking off from the RA for Samples 1 to 10 while Figure 13 shows the testing result of the ordinary aggregate.

$<$ Table 1 $>$

$<$ Figures 3 to $13>$

From the above results, it shows that the ordinary aggregate (Sample 11) has zero percent of cement portion flaking off while Sample 8 has an index of about 17.65, representing the largest quantity of cement mortar flaking off from the RA. Sample 8 was collected from a demolition site with a service life of forty years, with the worst concrete quality compared to the rest of the samples. Furthermore, Samples 1, 4, 5 and 10 with CSAggregate indices of about 13.07, 13.25, 13.37 and 13.61 respectively were collected from demolition sites with service lives of twentyfive to thirty years. For the other samples (Samples 2, 3, 6, 7 and 9), they were obtained from demolition sites with service lives of ten to twenty years with better CSAggregate indices. From 
this, it can be inferred that the quality of RA is inversely proportional to the years of services of buildings from where the RA was obtained. Similar results for $10 \mathrm{~mm}$ aggregate are obtained. The overall results are summarized in Table 2 .

$<$ Table 2>

\section{Verification of CSAggregate Index}

To verify the reliability of the newly developed classification method: CSAggregate, its relations with the most commonly used yardsticks for assessing the quality of RA: water absorption and density are explored. The results show that the CSAggregate Index and water absorption have a direct relationship with an R-square value of about 0.8799 (see Table 3 and Figure 14) for 10mm and about 0.8049 (see Table 3 and Figure 15) for 20mm aggregate. Equation (2) and Equation (3) can be used to transform the CSAggregate index into the water absorption rates for $10 \mathrm{~mm}$ and 20mm aggregate respectively.

CSAggregate Index $x_{10 \mathrm{~mm}}=0.7009 \times \mathrm{WA}_{10 \mathrm{~mm}}-0.0659$ Equation (2)

CSAggregate Index $20 \mathrm{~mm}=1.8884 \times \mathrm{WA}_{20 \mathrm{~mm}}-1.0844$ Equation (3)

where CSAggregate Index $x_{10 \mathrm{~mm}}$ is the Index for $10 \mathrm{~mm}$ aggregate; $\mathrm{WA}_{10 \mathrm{~mm}}$ the water absorption rate for $10 \mathrm{~mm}$ aggregate; CSAggregate Index $20 \mathrm{~mm}$ the Index for $20 \mathrm{~mm}$ aggregate; and $\mathrm{WA}_{20 \mathrm{~mm}}$ the water absorption rate for $20 \mathrm{~mm}$ aggregate.

$<$ Table 3>

$<$ Figure 14 $>$

$<$ Figure 15> 
Similarly, the relations between the CSAggregate index and density are explored. The results show that the CSAggregate Index and density are positively correlated with an R-square value of about 0.8102 for $10 \mathrm{~mm}$ (see Table 4 and Figure 16) and about 0.7698 (see Table 4 and Figure 17) for 20mm. Likewise, Equations (4) and (5) can be used to transform density into the CSAggregate index for $10 \mathrm{~mm}$ and $20 \mathrm{~mm}$ aggregate respectively.

$$
\begin{array}{ll}
\text { CSAggregate Index }_{10 \mathrm{~mm}}=-10.837 \times D_{10 \mathrm{~mm}}+28.501 & \text { Equation (4) } \\
\text { CSAggregate Index }_{20 \mathrm{~mm}}=-26.961 \times D_{20 \mathrm{~mm}}+70.602 & \text { Equation (5) }
\end{array}
$$

where $D_{10 \mathrm{~mm}}$ is the density for $10 \mathrm{~mm}$ aggregate; and $\mathrm{D}_{20 \mathrm{~mm}}$ the density for $20 \mathrm{~mm}$ aggregate.

$<$ Table 4>

$<$ Figure 16>

$<$ Figure 17>

\section{Conclusion}

There are a number of classification systems for recycled aggregate worldwide. However, most of these methods cannot provide a direct measurement of the cement mortar remains on the surface of RA, which however is the key factor determining the behaviour of recycled aggregate concrete. A new classification system for assessing the cement paste remains: CSAggregate, is developed in this paper. The CSAggregate Index is proven to be reliable and its validity is confirmed by comparing the index with other evaluation yardsticks: water absorption and density. The process of assessing the CSAggregate index is described which demonstrates that it is a speedier and easier method when compared with other approaches. The study also reveals that 
the quality of RA is inversely proportional to the years of service of the building structure from where the RA is generated.

It is generally agreed that the weakest link in RA comes from the cement paste remains that make the RA higher water absorption rates and lower densities. These directly affect the behaviour of RA and recycled aggregate concrete. Traditionally, both water absorption and density are measured in order to classify RA for different structural and non-structural applications. The high correlation between the CSAggregate index, water absorption and density of RA confirms that the use of CSAggregate index to assess the quality of RA is valid. Meanwhile, evaluation is more direct and the process is simpler and more straightforward. This infers that the new method can replace the traditional time-consuming classification methods.

\section{Acknowledgments}

The work described in this paper was fully supported by a grant from the Housing Authority Research Fund of the Hong Kong Special Administrative Region, China (Project Ref. No. 9460004).

\section{References}

[1] Mindess, S. Young, F. Darwin D., Concrete, Upper Saddle River, NJ: Prentice Hall, 2003.

[2] BD (Buildings Department), Practice note for authorized persons and registered structured engineers: use of recycled aggregates in concrete, Buildings Department, Hong Kong Government, 2003. 
[3] DIN 4226-100, Aggregates for mortar and concrete: part 100 recycled aggregates, Beuth Verlag GmbH, Germany, 2002.

[4] Hendriks C.F., Pietersen H.S., Sustainable raw materials: construction and demolition waste, Cachan Cedex, France: RILEM Publication, 2000.

[5] Vyncke J., Rousseau E., Recycling of construction and demolition waste in Belgium: actual situation and future evaluation, Demolition and Reuse of Concrete and Masonry: Guidelines for Demolition and Reuse of Concrete and Masonry: Proceedings of the Third International RILEM Symposium on Demolition and Reuse of Concrete Masonry, 24-27 October 1993, 1993, London: E\&FN Spon, 57-69.

[6] Tomosawa F., Noguchi T., New technology for the recycling of concrete - Japanese experience, Concrete technology for a sustainable development in the 21st century, London: New York: E \& FN Spon, 2000, 274-287.

[7] Lai J.S., Materials of construction, Georgia Institute of Technology, Kendall / Hunt Publishing Company, 4050 Westmark Drive, Dubuque, Iowa 52002, 1999.

[8] BS (British Standard) 882, Specification for aggregates from natural sources for concrete, British Standards Institution, London, United Kingdom, 1992.

[9] Hansen T.C., Recycling of demolished concrete and masonry: report of Technical Committee 37-DRC, Demolition and Reuse of Concrete, RILEM (the International Union of Testing and Research Laboratories for Materials and Structures), London: E \& FN Spon, 1992.

[10] Barra M., Vazquez E., Properties of concretes with recycled aggregates: influence of properties of the aggregates and their interpretation, Sustainable construction: use of recycled concrete aggregate: proceedings of the international symposium organized by the concrete technology unit, University of Dundee and held at the Department of Trade and 
Industry Conference Centre, London, UK on 11-12 November 1998, London: Thomas Telford, 1998, 19-30. 
Table 1a: The Results of Classification System on Cement Portion Remains: CSAggregate

\begin{tabular}{|c|c|c|c|c|c|c|c|}
\hline Sample & $\mathrm{i}$ & $\mathrm{S}_{\mathrm{i}}(\mathrm{mm})$ & $\mathrm{P}_{\mathrm{i}, \mathrm{b}}(\%)$ & $\mathrm{P}_{\mathrm{i}, \mathrm{a}}(\%)$ & $\mathrm{P}_{\mathrm{i}, \mathrm{a}}-\mathrm{P}_{\mathrm{i}, \mathrm{b}}(\%)$ & $\frac{\left.\left(P_{i, a}-P_{i, b}\right)+\left(P_{i-1, a}-P_{i-1, b}\right)\right)\left(S_{i}-S_{i-1}\right)}{2}$ & $\begin{array}{l}\text { CSAggregate } \\
\text { Index }\end{array}$ \\
\hline \multirow{6}{*}{1} & 0 & 0 & 0.00 & 0.00 & 0.00 & 0.00 & \multirow{6}{*}{13.07} \\
\hline & 1 & 5 & 0.32 & 9.30 & 8.98 & 0.22 & \\
\hline & 2 & 10 & 5.77 & 22.61 & 16.84 & 0.65 & \\
\hline & 3 & 14 & 25.59 & 47.41 & 21.82 & 0.77 & \\
\hline & 4 & 20 & 83.62 & 89.84 & 6.22 & 0.84 & \\
\hline & 5 & 28 & 100.00 & 100.00 & 0.00 & 0.25 & \\
\hline \multirow{6}{*}{2} & 0 & 0 & 0.00 & 0.00 & 0.00 & 0.00 & \multirow{6}{*}{4.57} \\
\hline & 1 & 5 & 0.93 & 4.29 & 0.93 & 0.08 & \\
\hline & 2 & 10 & 9.02 & 15.94 & 9.02 & 0.26 & \\
\hline & 3 & 14 & 42.35 & 52.30 & 42.35 & 0.34 & \\
\hline & 4 & 20 & 93.96 & 94.80 & 93.96 & 0.32 & \\
\hline & 5 & 28 & 100.00 & 100.00 & 100.00 & 0.03 & \\
\hline \multirow{6}{*}{3} & 0 & 0 & 0.00 & 0.00 & 0.00 & 0.00 & \multirow{6}{*}{8.49} \\
\hline & 1 & 5 & 0.46 & 5.25 & 4.79 & 0.12 & \\
\hline & 2 & 10 & 6.55 & 18.53 & 11.98 & 0.42 & \\
\hline & 3 & 14 & 29.61 & 44.39 & 14.78 & 0.54 & \\
\hline & 4 & 20 & 83.35 & 87.29 & 3.94 & 0.56 & \\
\hline & 5 & 28 & 100.00 & 100.00 & 0.00 & 0.16 & \\
\hline \multirow{6}{*}{4} & 0 & 0 & 0.00 & 0.00 & 0.00 & 0.00 & \multirow{6}{*}{13.25} \\
\hline & 1 & 5 & 0.15 & 7.27 & 7.11 & 0.18 & \\
\hline & 2 & 10 & 5.26 & 24.39 & 19.14 & 0.66 & \\
\hline & 3 & 14 & 28.12 & 45.38 & 17.26 & 0.73 & \\
\hline & 4 & 20 & 76.92 & 86.07 & 9.14 & 0.79 & \\
\hline & 5 & 28 & 100.00 & 100.00 & 0.00 & 0.37 & \\
\hline \multirow{6}{*}{5} & 0 & 0 & 0.00 & 0.00 & 0.00 & 0.00 & \multirow{6}{*}{13.37} \\
\hline & 1 & 5 & 0.75 & 9.76 & 9.01 & 0.23 & \\
\hline & 2 & 10 & 5.89 & 24.09 & 18.20 & 0.68 & \\
\hline & 3 & 14 & 24.48 & 46.52 & 22.04 & 0.80 & \\
\hline & 4 & 20 & 85.95 & 92.28 & 6.33 & 0.85 & \\
\hline & 5 & 28 & 100.00 & 100.00 & 0.00 & 0.25 & \\
\hline \multirow{6}{*}{6} & 0 & 0 & 0.00 & 0.00 & 0.00 & 0.11 & \multirow{6}{*}{6.22} \\
\hline & 1 & 5 & 0.28 & 4.75 & 4.47 & 0.29 & \\
\hline & 2 & 10 & 6.19 & 13.46 & 7.27 & 0.40 & \\
\hline & 3 & 14 & 24.72 & 37.58 & 12.86 & 0.44 & \\
\hline & 4 & 20 & 87.06 & 88.78 & 1.72 & 0.07 & \\
\hline & 5 & 28 & 100.00 & 100.00 & 0.00 & 0.11 & \\
\hline \multirow{6}{*}{7} & 0 & 0 & 0.00 & 0.00 & 0.00 & 0.00 & \multirow{6}{*}{10.16} \\
\hline & 1 & 5 & 5.86 & 15.68 & 9.82 & 0.25 & \\
\hline & 2 & 10 & 16.86 & 29.12 & 12.26 & 0.55 & \\
\hline & 3 & 14 & 33.35 & 47.08 & 13.73 & 0.52 & \\
\hline & 4 & 20 & 66.14 & 71.70 & 5.56 & 0.58 & \\
\hline & 5 & 28 & 100.00 & 100.00 & 0.00 & 0.22 & \\
\hline \multirow{6}{*}{8} & 0 & 0 & 0.00 & 0.00 & 0.00 & 0.00 & \multirow{6}{*}{17.65} \\
\hline & 1 & 5 & 0.44 & 11.38 & 11.22 & 0.28 & \\
\hline & 2 & 10 & 5.98 & 27.12 & 17.80 & 0.73 & \\
\hline & 3 & 14 & 22.77 & 55.74 & 24.14 & 0.84 & \\
\hline & 4 & 20 & 81.91 & 89.06 & 6.73 & 0.93 & \\
\hline & 5 & 28 & 100.00 & 100.00 & 0.00 & 0.27 & \\
\hline
\end{tabular}


Table 1b: The Results of Classification System on Cement Portion Remains: CSAggregate

\begin{tabular}{|c|c|c|c|c|c|c|c|}
\hline Sample & i & $\mathrm{S}_{\mathrm{i}}(\mathrm{mm})$ & $\mathrm{P}_{\mathrm{i}, \mathrm{b}}(\%)$ & $P_{i, a}(\%)$ & $\mathrm{P}_{\mathrm{i}, \mathrm{a}}-\mathrm{P}_{\mathrm{i}, \mathrm{b}}(\%)$ & $\frac{\left[\left(P_{i, a}-P_{i, b}\right)+\left(P_{i-1, a}-P_{i-1, b}\right)\right]\left(S_{i}-S_{i-1}\right)}{2}$ & $\begin{array}{l}\text { CSAggregate } \\
\text { Index }\end{array}$ \\
\hline \multirow{6}{*}{9} & 0 & 0 & 0.00 & 0.00 & 0.00 & 0.00 & \multirow{6}{*}{7.05} \\
\hline & 1 & 5 & 0.39 & 5.61 & 5.22 & 0.24 & \\
\hline & 2 & 10 & 6.66 & 15.44 & 8.78 & 0.70 & \\
\hline & 3 & 14 & 31.01 & 41.16 & 10.15 & 0.65 & \\
\hline & 4 & 20 & 80.99 & 85.56 & 4.57 & 0.53 & \\
\hline & 5 & 28 & 100.00 & 100.00 & 0.00 & 0.14 & \\
\hline \multirow{6}{*}{10} & 0 & 0 & 0.00 & 0.00 & 0.00 & 0.00 & \multirow{6}{*}{13.61} \\
\hline & 1 & 5 & 0.59 & 11.29 & 10.70 & 0.27 & \\
\hline & 2 & 10 & 10.69 & 27.49 & 16.80 & 0.69 & \\
\hline & 3 & 14 & 23.51 & 47.95 & 24.45 & 0.82 & \\
\hline & 4 & 20 & 78.83 & 83.19 & 4.36 & 0.86 & \\
\hline & 5 & 28 & 100.00 & 100.00 & 0.00 & 0.17 & \\
\hline \multirow{6}{*}{11} & 0 & 0 & $0.00 \%$ & 0.00 & 0.00 & 0.00 & \multirow{6}{*}{0.00} \\
\hline & 1 & 5 & 0.39 & 0.39 & 0.00 & 0.00 & \\
\hline & 2 & 10 & 15.11 & 15.11 & 0.00 & 0.00 & \\
\hline & 3 & 14 & 49.41 & 49.41 & 0.00 & 0.00 & \\
\hline & 4 & 20 & 92.91 & 92.91 & 0.00 & 0.00 & \\
\hline & 5 & 28 & 100.00 & 100.00 & 0.00 & 0.00 & \\
\hline
\end{tabular}


Table 2: Results for CSAggregate Index

\begin{tabular}{|c|c|c|}
\hline \multirow{2}{*}{ Sample } & \multicolumn{2}{|c|}{ CSAggregate Index } \\
\cline { 2 - 3 } & $10 \mathrm{~mm}$ & $20 \mathrm{~mm}$ \\
\hline 1 & 5.32 & 13.07 \\
\hline 2 & 2.45 & 4.57 \\
\hline 3 & 3.49 & 8.49 \\
\hline 4 & 5.02 & 13.25 \\
\hline 5 & 4.97 & 13.37 \\
\hline 6 & 3.32 & 6.22 \\
\hline 7 & 4.75 & 10.16 \\
\hline 8 & 6.58 & 17.65 \\
\hline 9 & 4.90 & 7.05 \\
\hline 10 & 5.57 & 13.61 \\
\hline 11 & 0.00 & 0.00 \\
\hline
\end{tabular}




\section{Table 3: CSAggregate Index and Water Absorption}

\begin{tabular}{|c|c|c|c|c|}
\hline \multirow{2}{*}{ Sample } & \multicolumn{2}{|c|}{ CSAggregate Index } & \multicolumn{2}{c|}{ Water Absorption (\%) } \\
\cline { 2 - 5 } & $10 \mathrm{~mm}$ & $20 \mathrm{~mm}$ & $10 \mathrm{~mm}$ & $20 \mathrm{~mm}$ \\
\hline 1 & 5.32 & 13.07 & 6.46 & 7.01 \\
\hline 2 & 2.45 & 4.57 & 2.87 & 1.64 \\
\hline 3 & 3.49 & 8.49 & 6.73 & 5.92 \\
\hline 4 & 5.02 & 13.25 & 7.48 & 7.39 \\
\hline 5 & 4.97 & 13.37 & 7.89 & 7.32 \\
\hline 6 & 3.32 & 6.22 & 5.16 & 5.74 \\
\hline 7 & 4.75 & 10.16 & 7.30 & 6.75 \\
\hline 8 & 6.58 & 17.65 & 9.40 & 8.18 \\
\hline 9 & 4.90 & 7.05 & 6.04 & 5.97 \\
\hline 10 & 5.57 & 13.61 & 7.10 & 6.69 \\
\hline 11 & 0.00 & 0.00 & 0.76 & 0.60 \\
\hline
\end{tabular}


Table 4: CSAggregate Index and Density

\begin{tabular}{|c|c|c|c|c|}
\hline \multirow{2}{*}{ Sample } & \multicolumn{2}{|c|}{ CSAggregate Index } & \multicolumn{2}{c|}{ Density $\left(\mathrm{Mg} / \mathrm{m}^{3}\right)$} \\
\cline { 2 - 5 } & $10 \mathrm{~mm}$ & $20 \mathrm{~mm}$ & $10 \mathrm{~mm}$ & $20 \mathrm{~mm}$ \\
\hline 1 & 5.32 & 13.07 & 2.22 & 2.13 \\
\hline 2 & 2.45 & 4.57 & 2.46 & 2.53 \\
\hline 3 & 3.49 & 8.49 & 2.20 & 2.20 \\
\hline 4 & 5.02 & 13.25 & 2.20 & 2.18 \\
\hline 5 & 4.97 & 13.37 & 2.10 & 2.20 \\
\hline 6 & 3.32 & 6.22 & 2.25 & 2.27 \\
\hline 7 & 4.75 & 10.16 & 2.15 & 2.19 \\
\hline 8 & 6.58 & 17.65 & 2.11 & 2.12 \\
\hline 9 & 4.90 & 7.05 & 2.16 & 2.24 \\
\hline 10 & 5.57 & 13.61 & 2.21 & 2.14 \\
\hline 11 & 0.00 & 0.00 & 2.59 & 2.62 \\
\hline
\end{tabular}




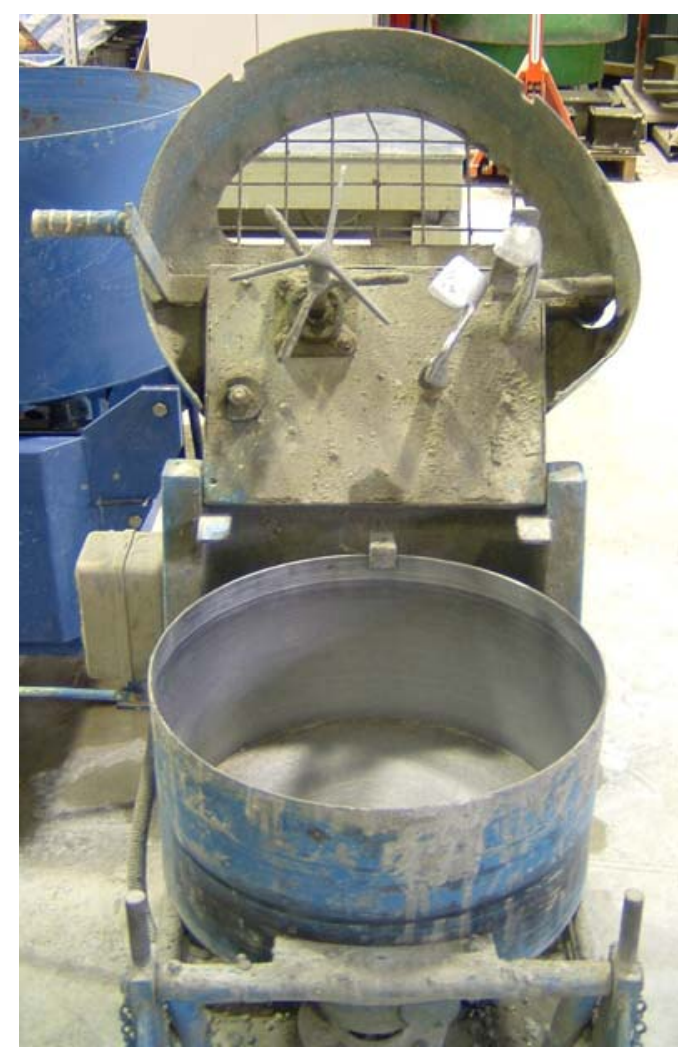

Figure 1: Mixer Adopted in the CSAggregate 


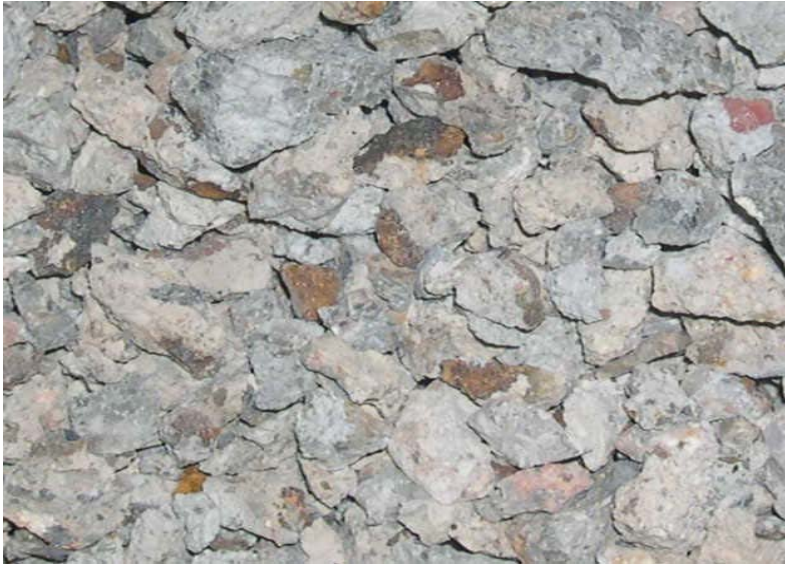

(i) Sample 1: Aggregate from Demolition Site 1

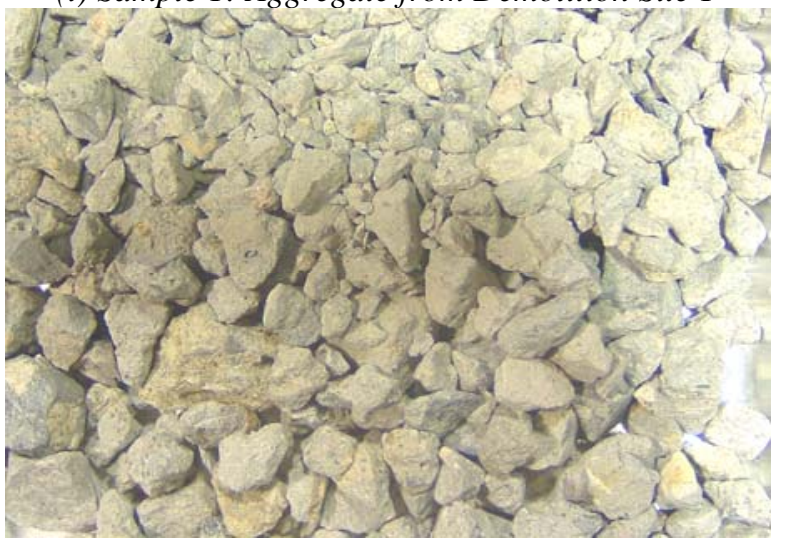

(iii) Sample 3: Aggregate from Demolition Site 3

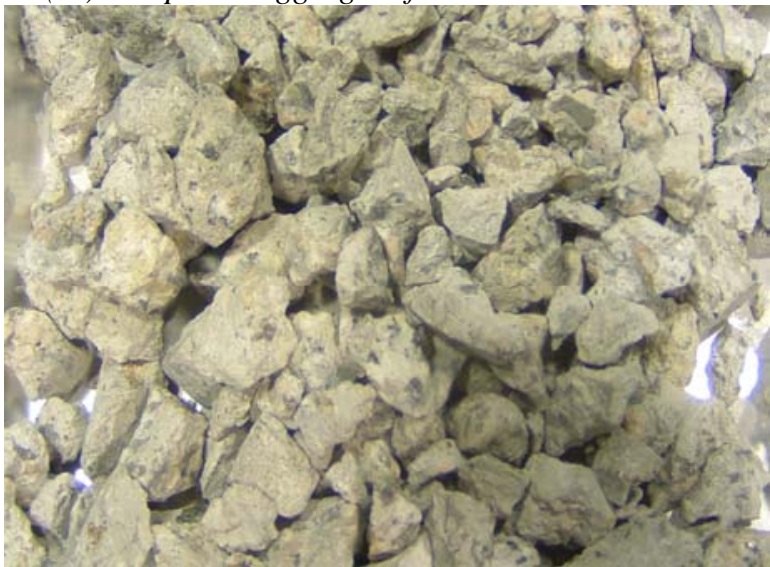

(v) Sample 5: Aggregate from Demolition Site 5

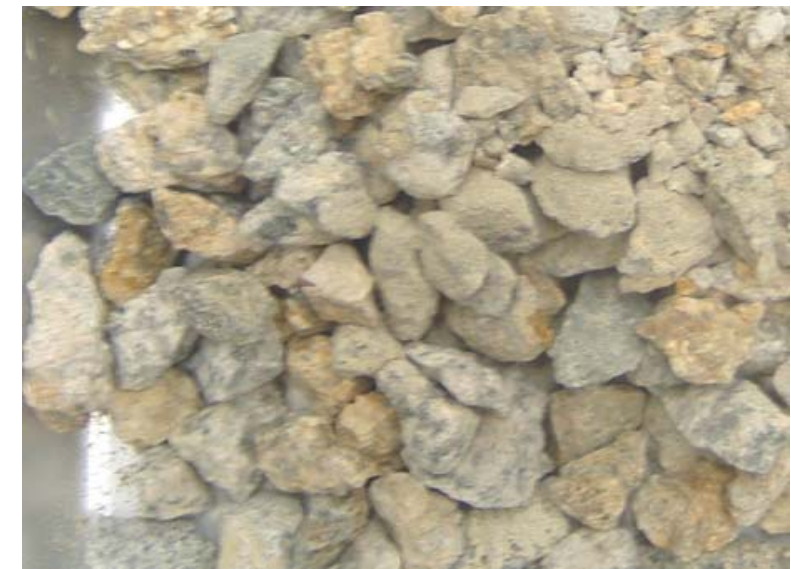

(ii) Sample 2: Aggregate from Demolition Site 2

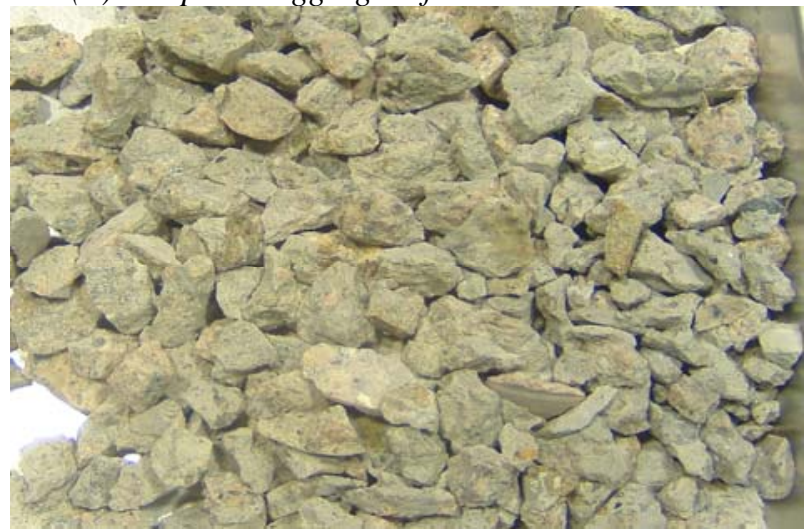

(iv) Sample 4: Aggregate from Demolition Site 4



(vi) Sample 6: Aggregate from Demolition Site 6 Figure 2a: Samples 1 to 11 Assessed Using CSAggregate 


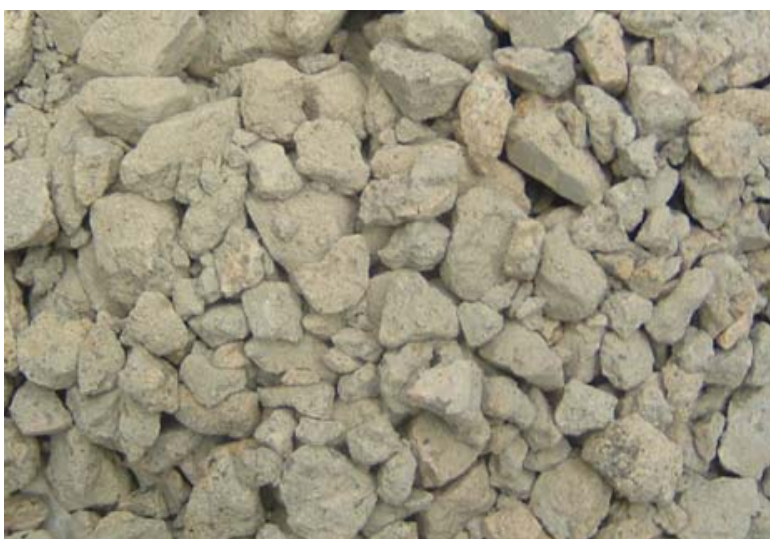

(vii) Sample 7: Aggregate from Demolition Site 7

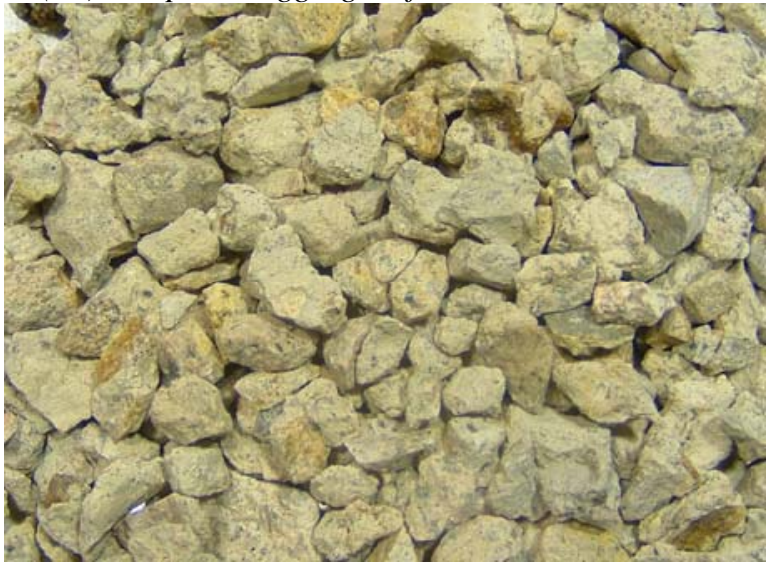

(ix) Sample 9: Aggregate from Demolition Site 9

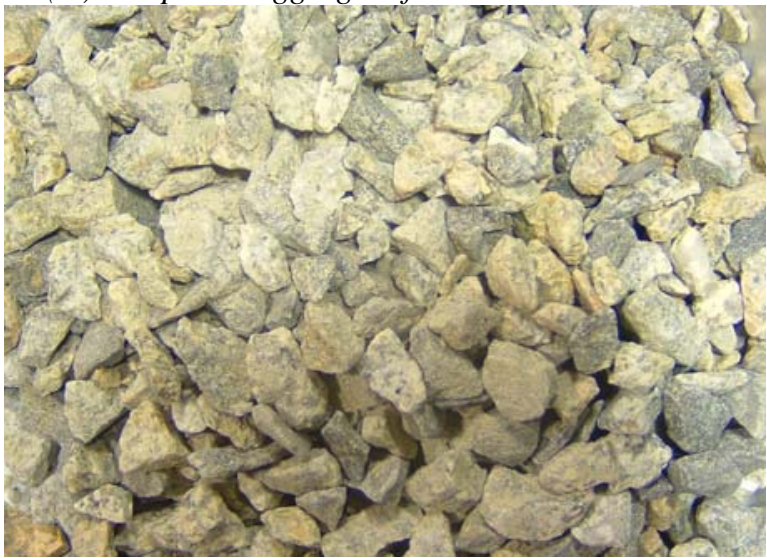

(xi) Sample 11: Aggregate from Ordinary Aggregate

Figure 2b: Samples 1 to 11 Assessed Using CSAggregate



(viii) Sample 8: Aggregate from Demolition Site 8

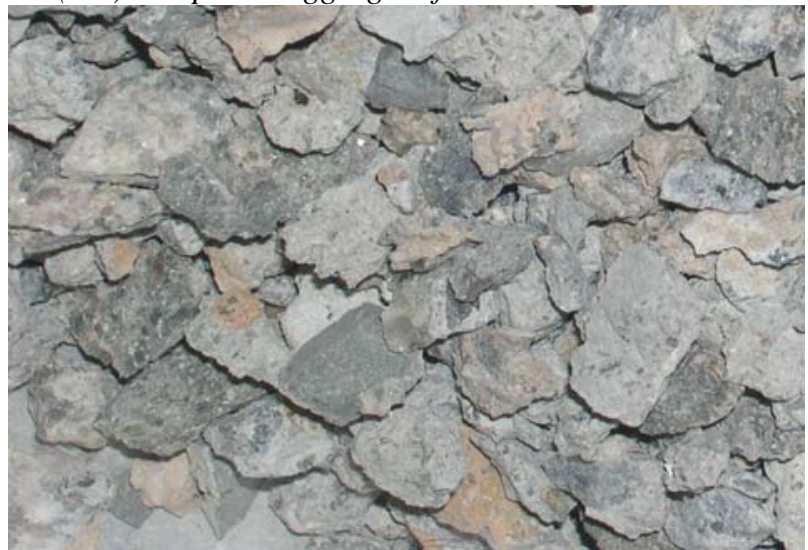

(x) Sample 10: Aggregate from Demolition Site 10 


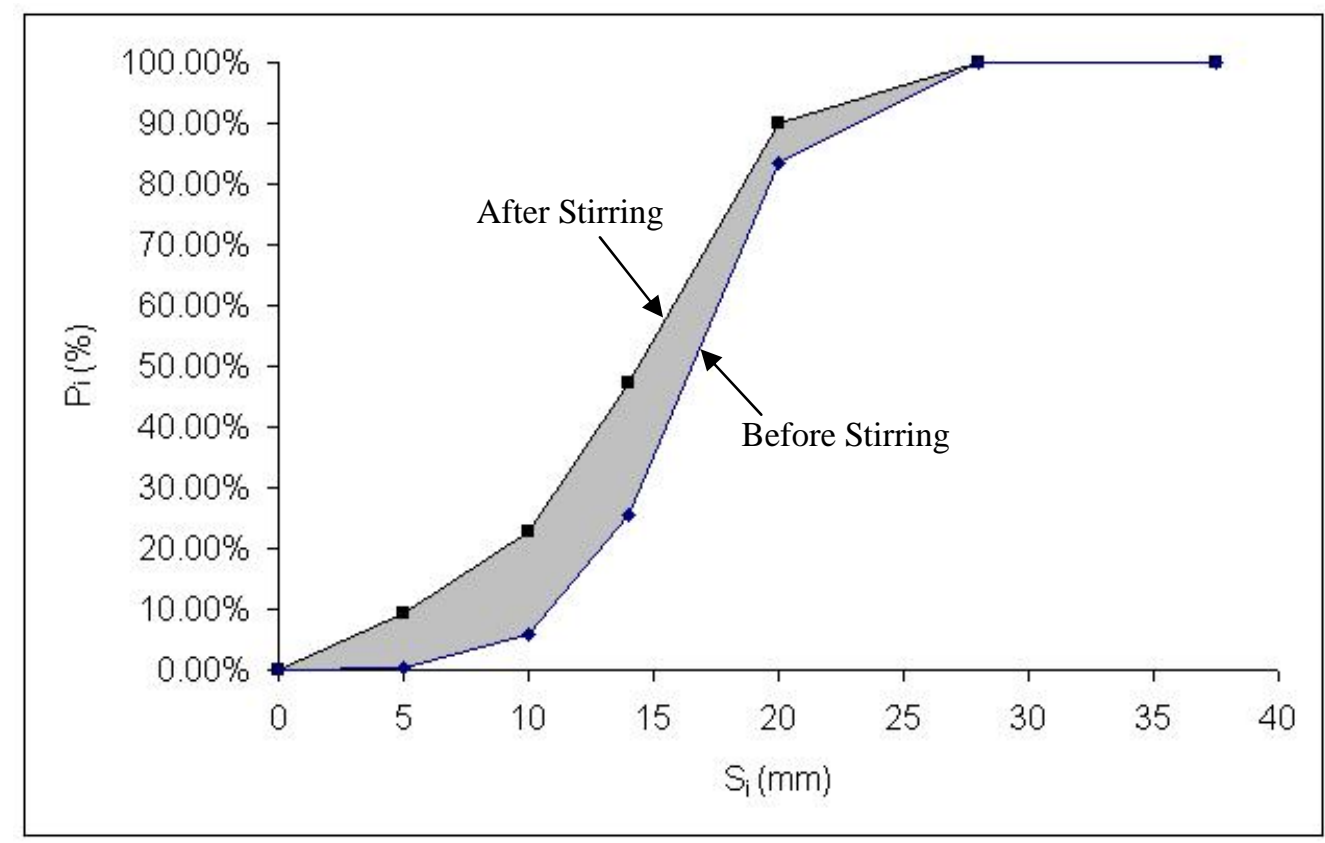

Figure 3: Result of CSAggregate for Sample 1 


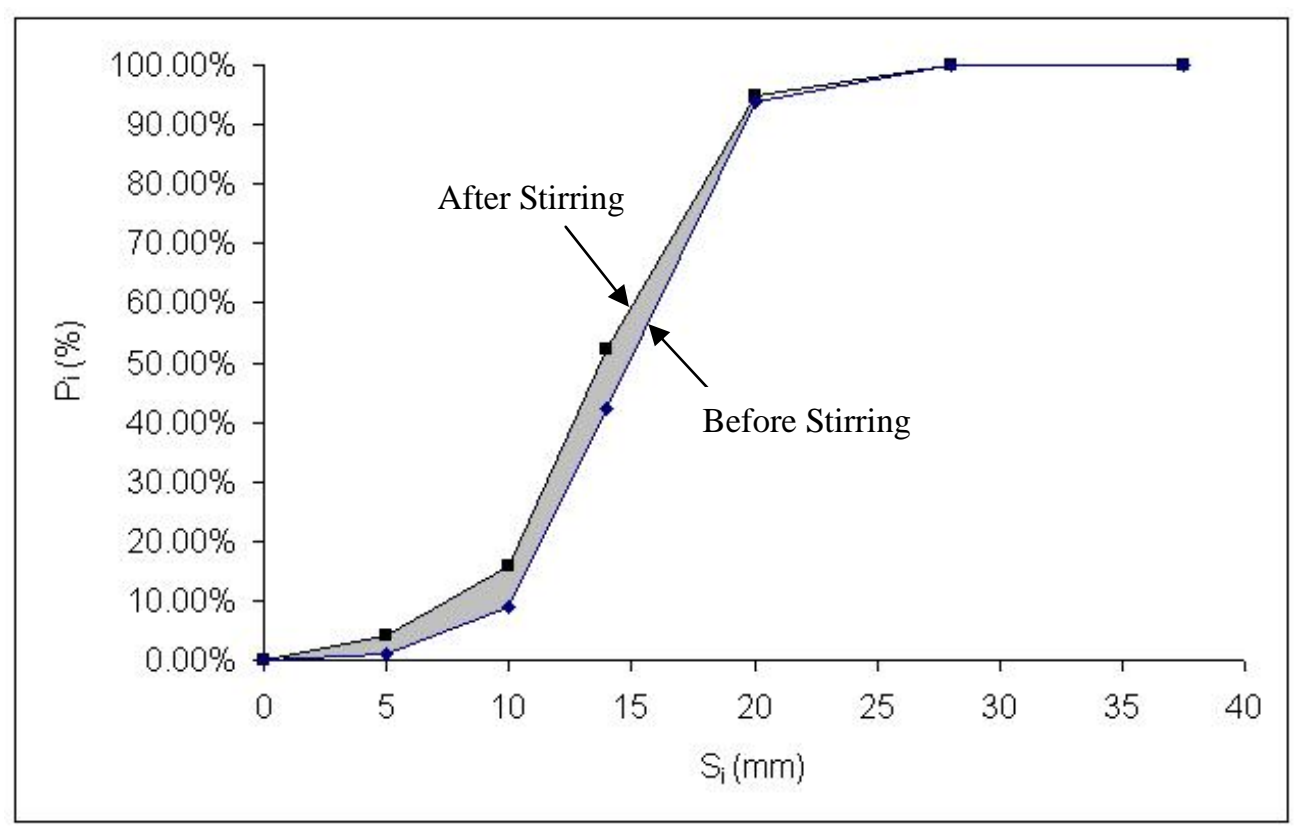

Figure 4: Result of CSAggregate for Sample 2 


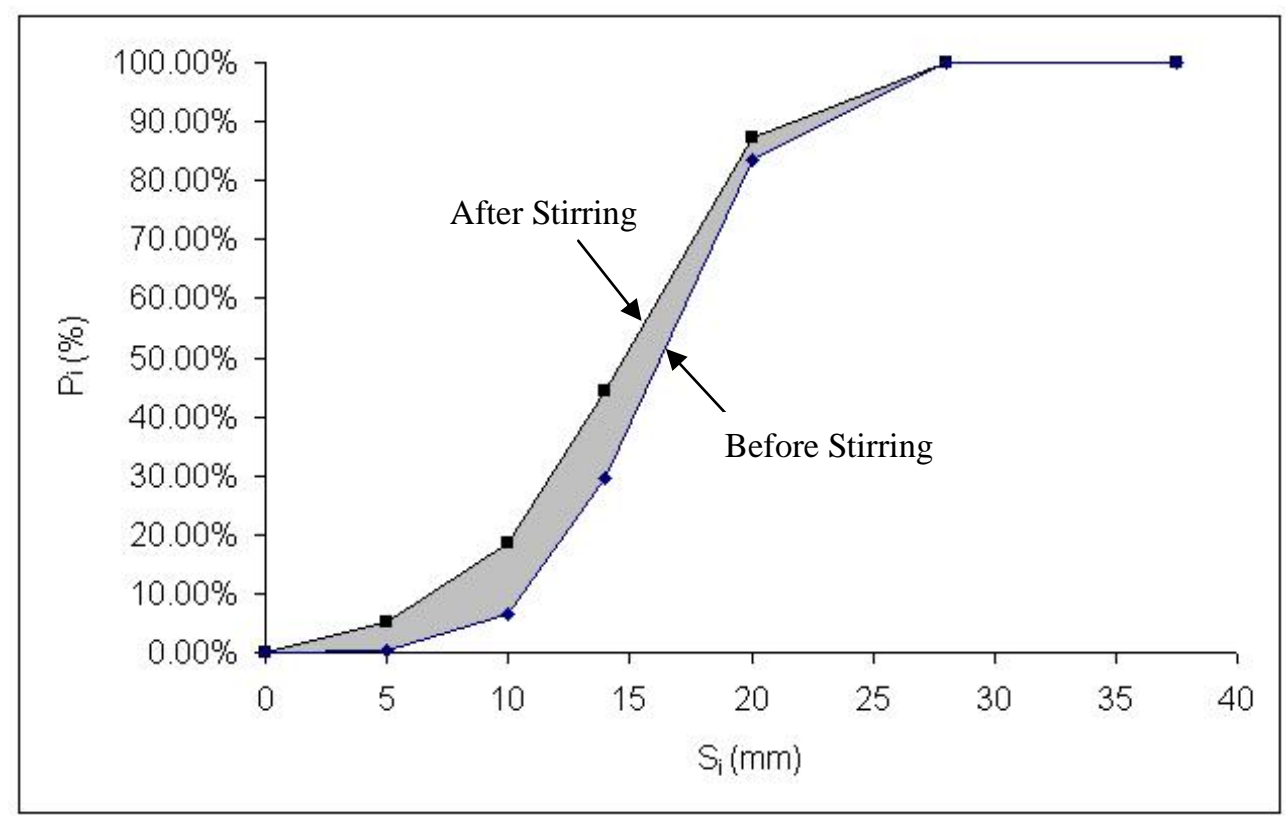

Figure 5: Result of CSAggregate for Sample 3 


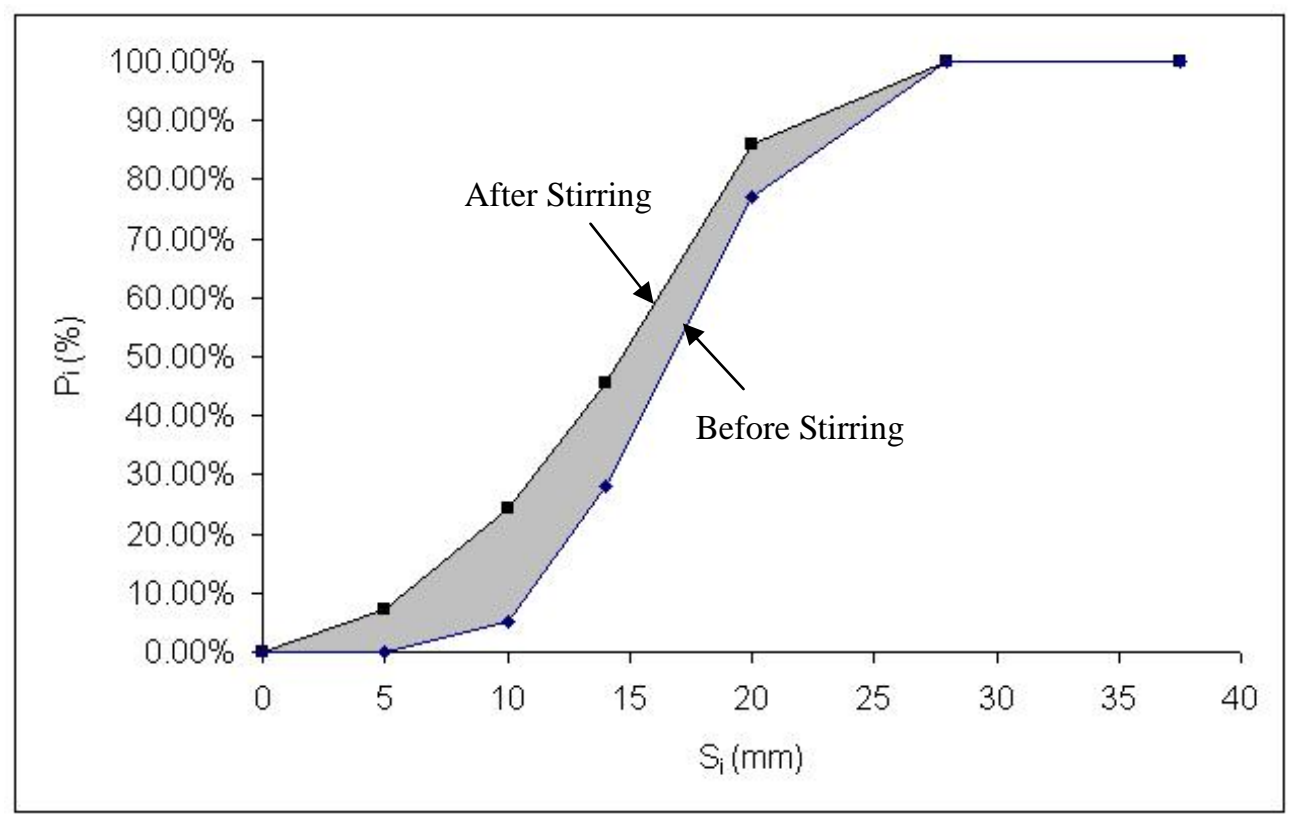

Figure 6: Result of CSAggregate for Sample 4 


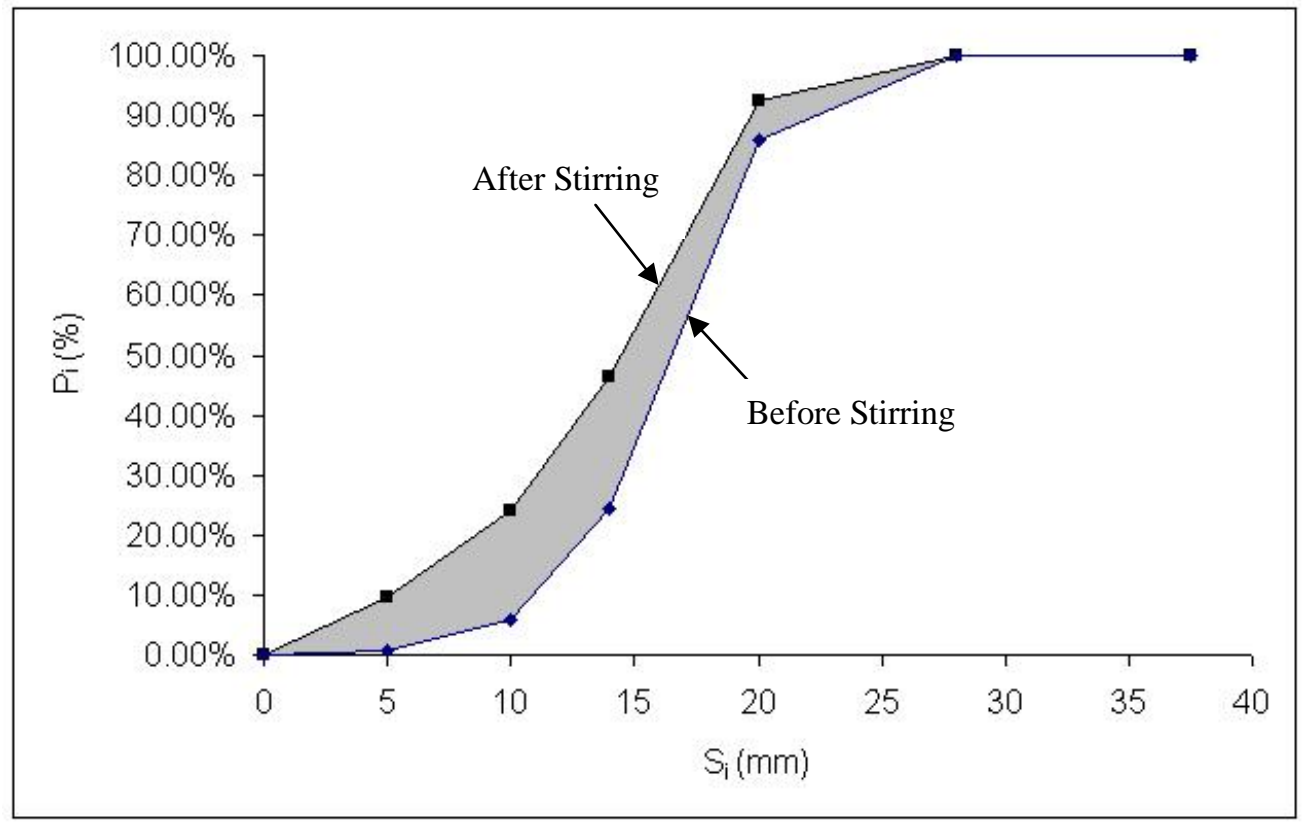

Figure 7: Result of CSAggregate for Sample 5 


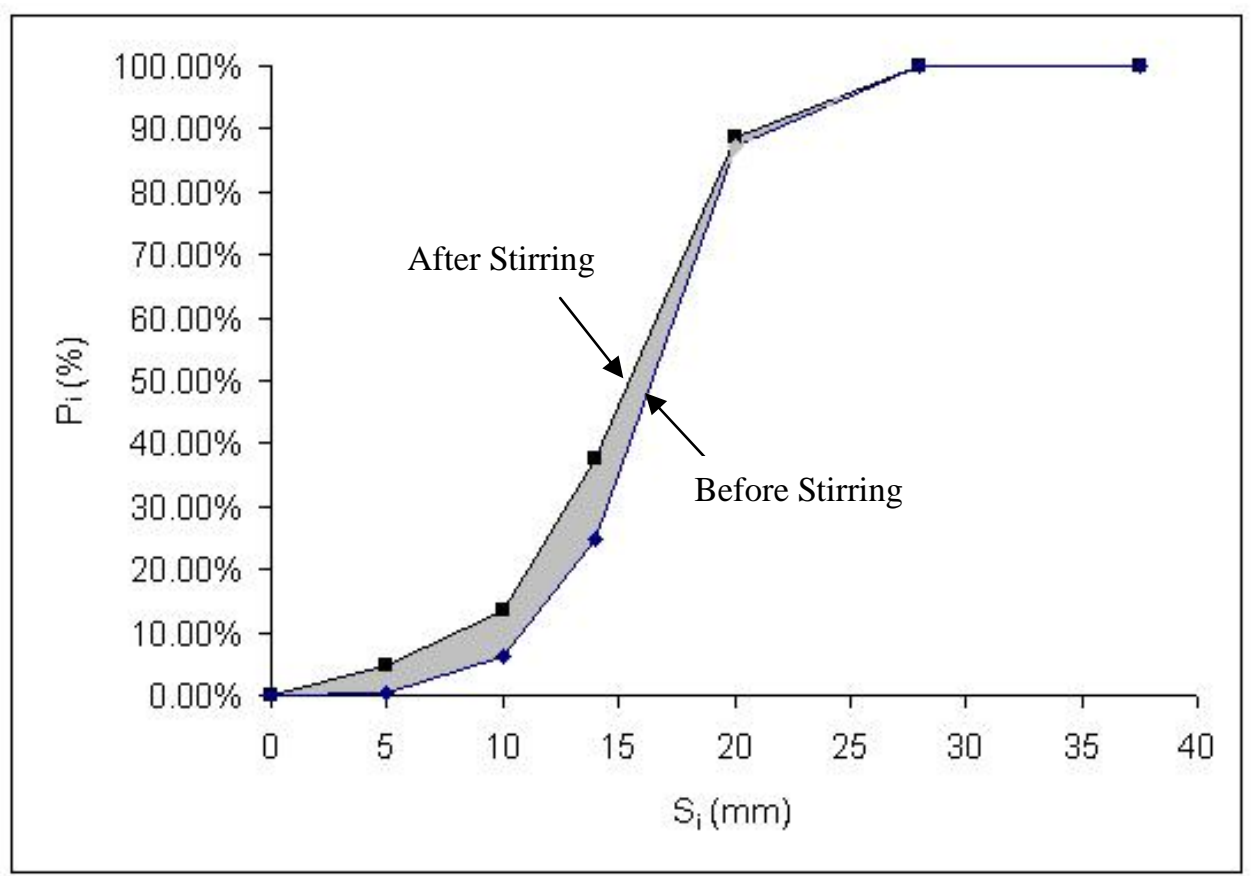

Figure 8: Result of CSAggregate for Sample 6 


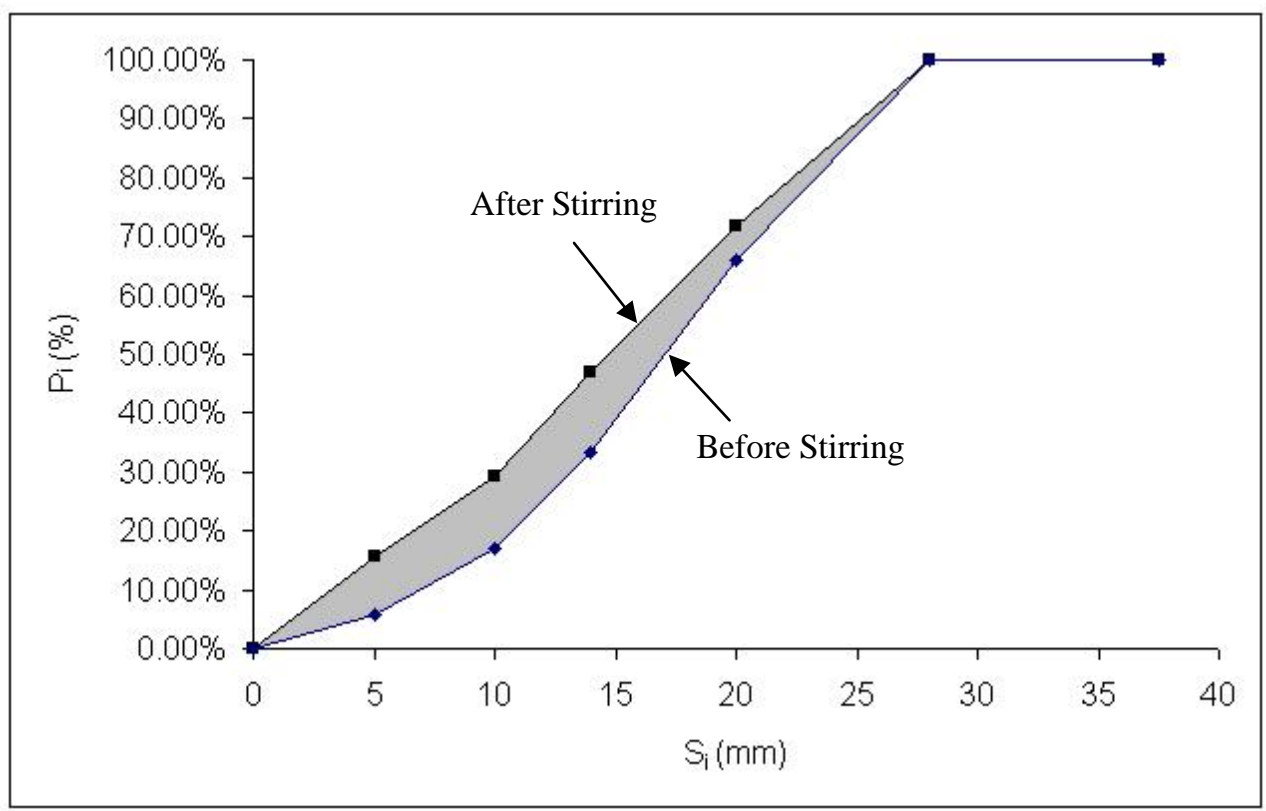

Figure 9: Result of CSAggregate for Sample 7 


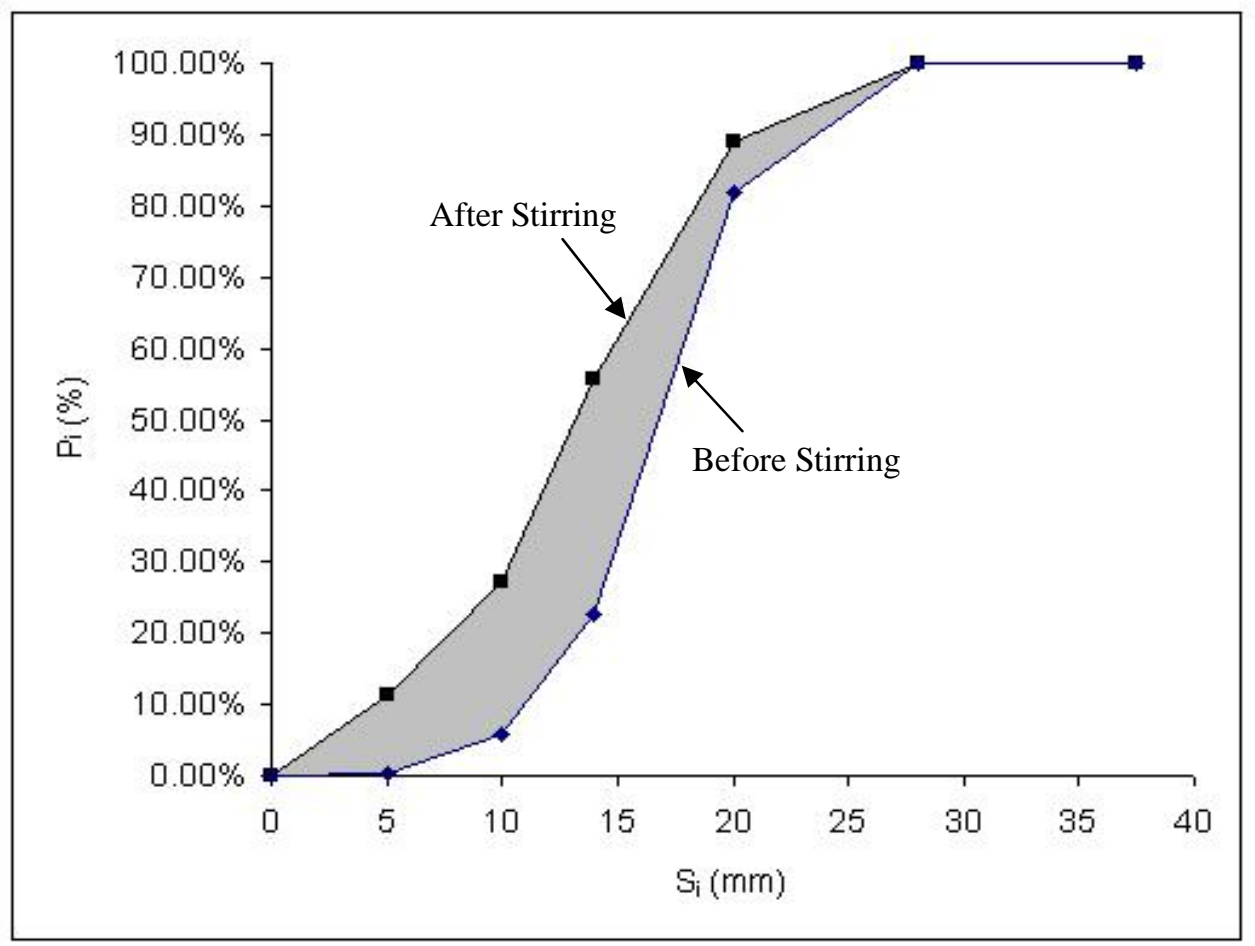

Figure 10: Result of CSAggregate for Sample 8 


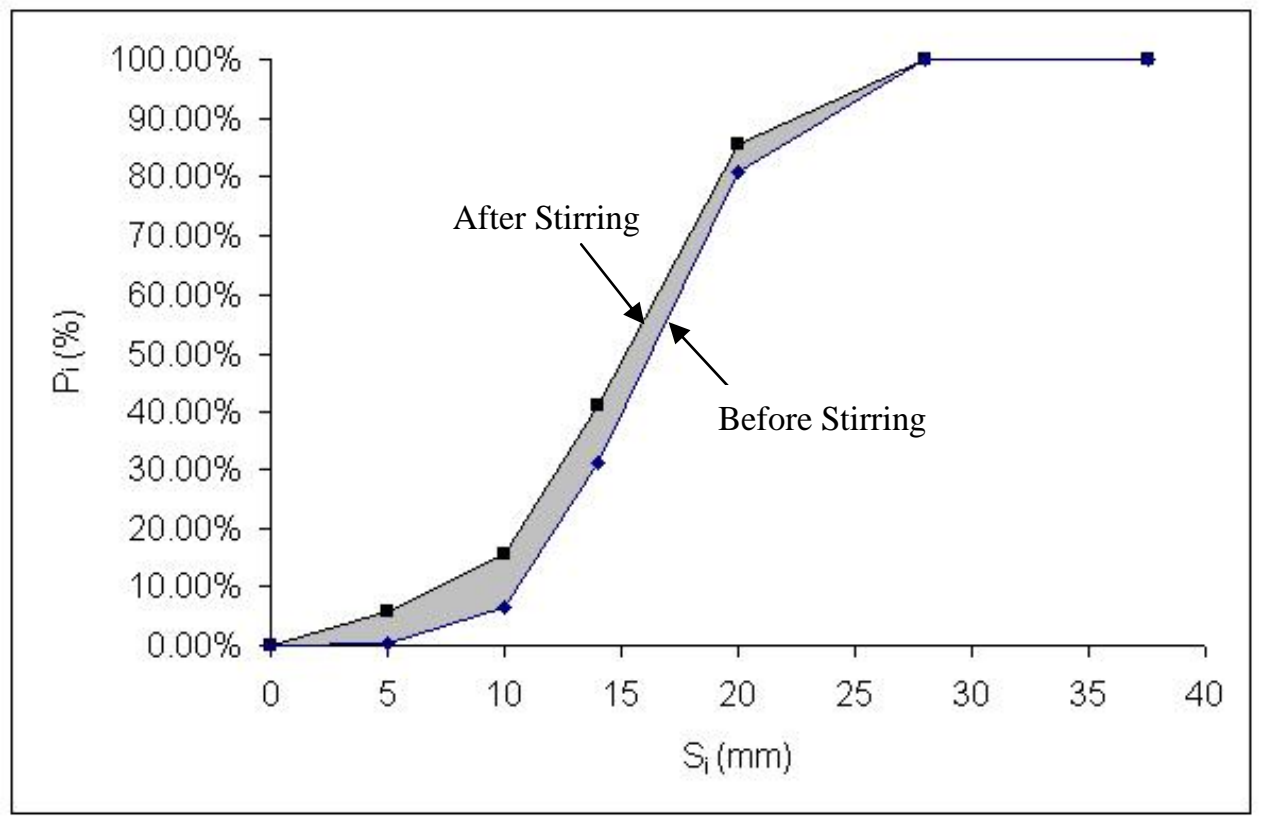

Figure 11: Result of CSAggregate for Sample 9 


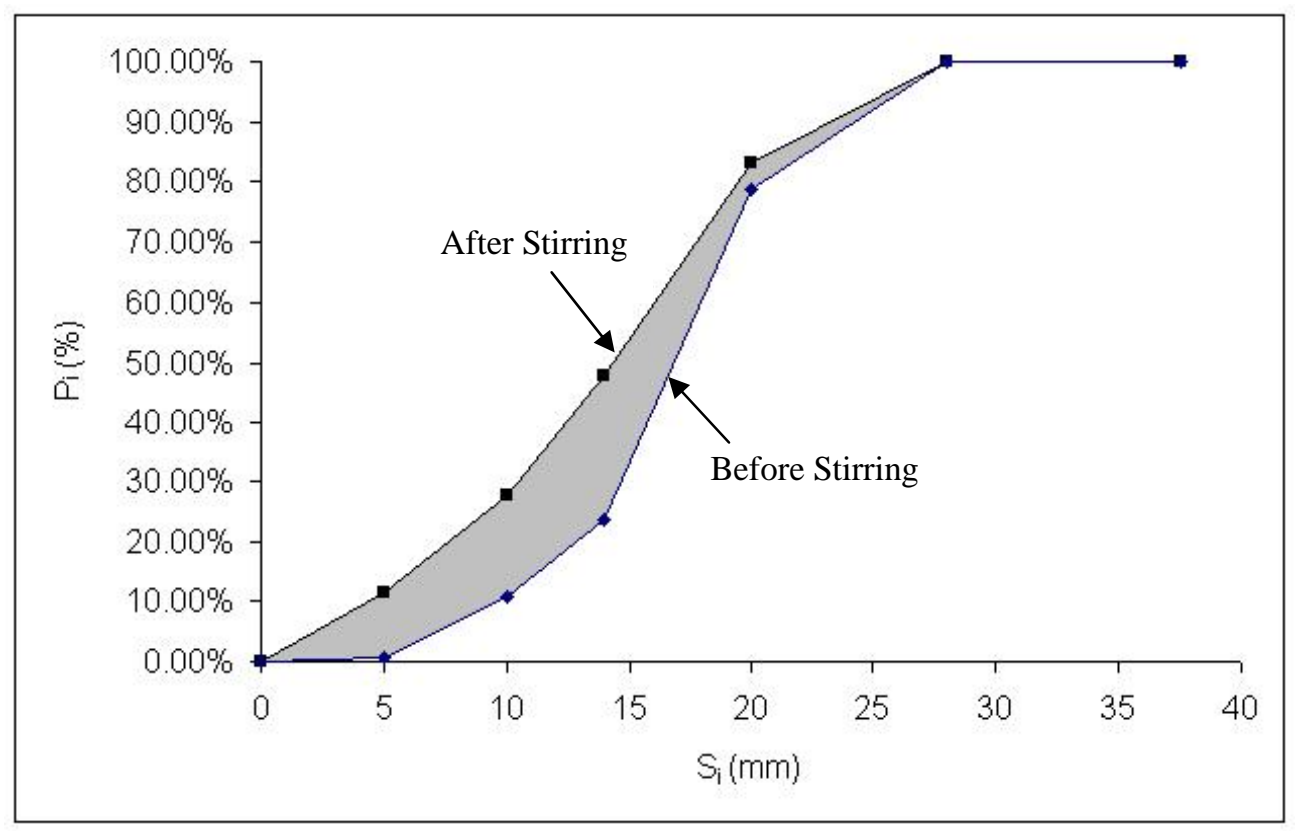

Figure 12: Result of CSAggregate for Sample 10 


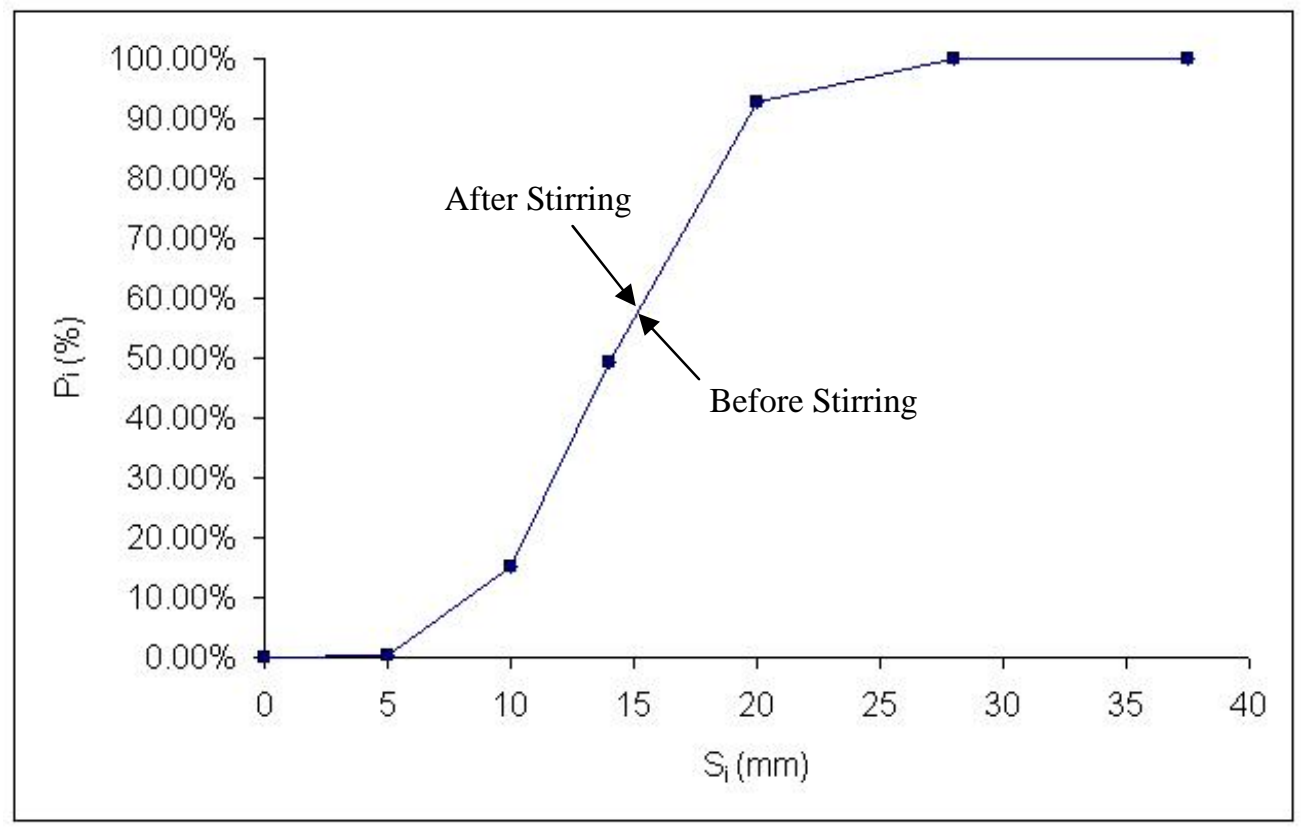

Figure 13: Result of CSAggregate for Sample 11 


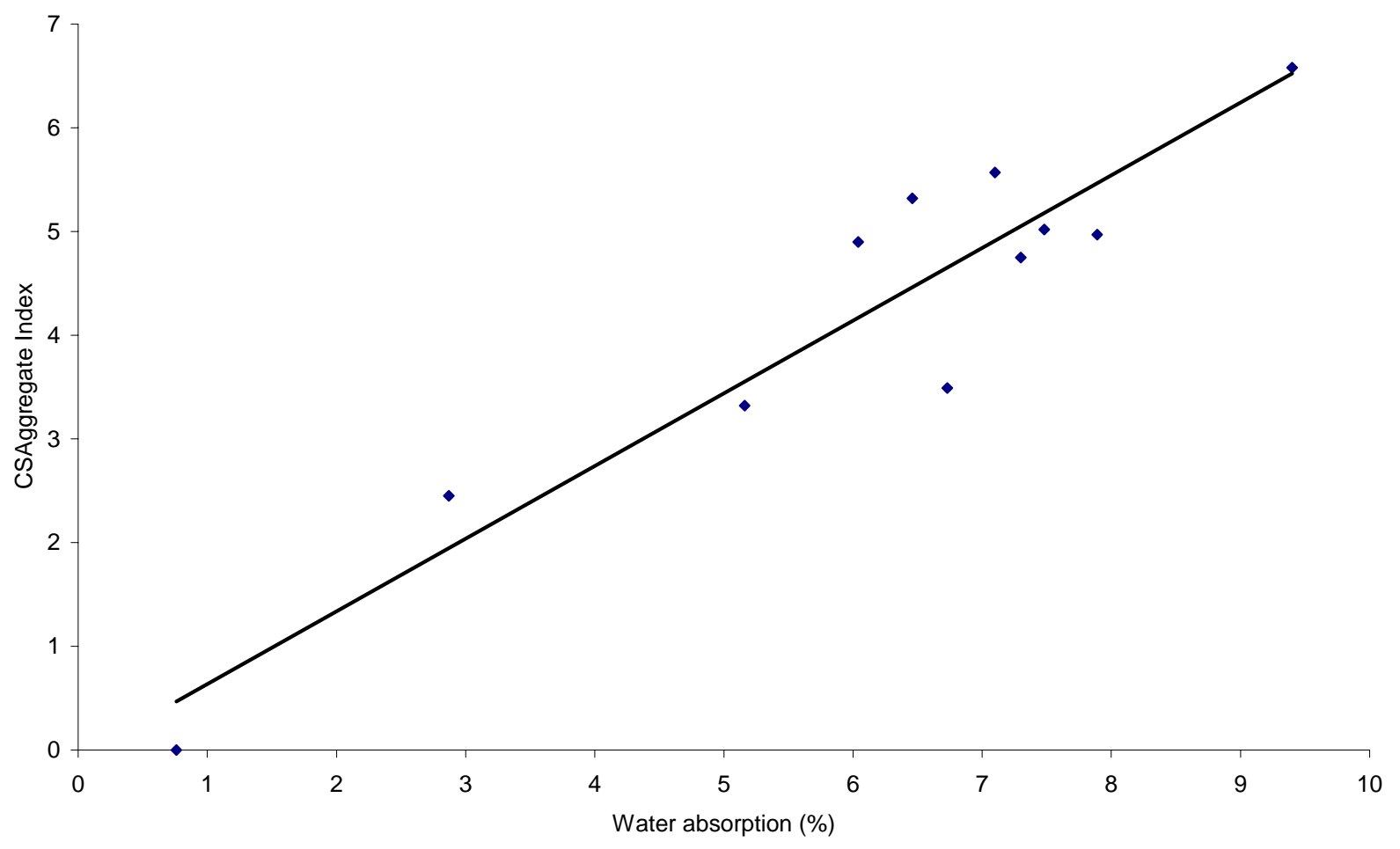

Figure 14: Relation of CSAggregate Index and Water Absorption Rates for 10mm Aggregate 


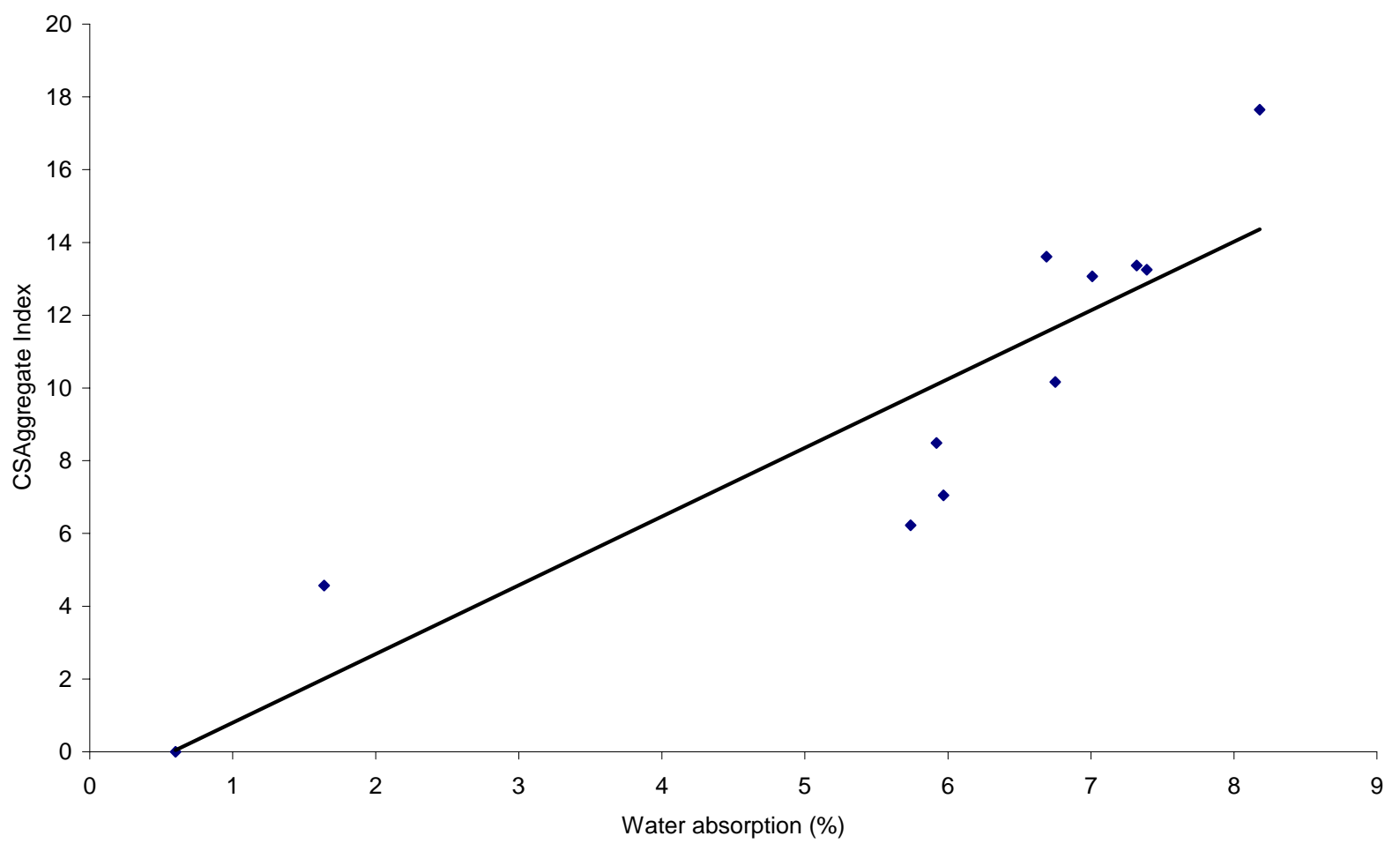

Figure 15: Relation of CSAggregate Index and Water Absorption Rates for 20mm Aggregate 


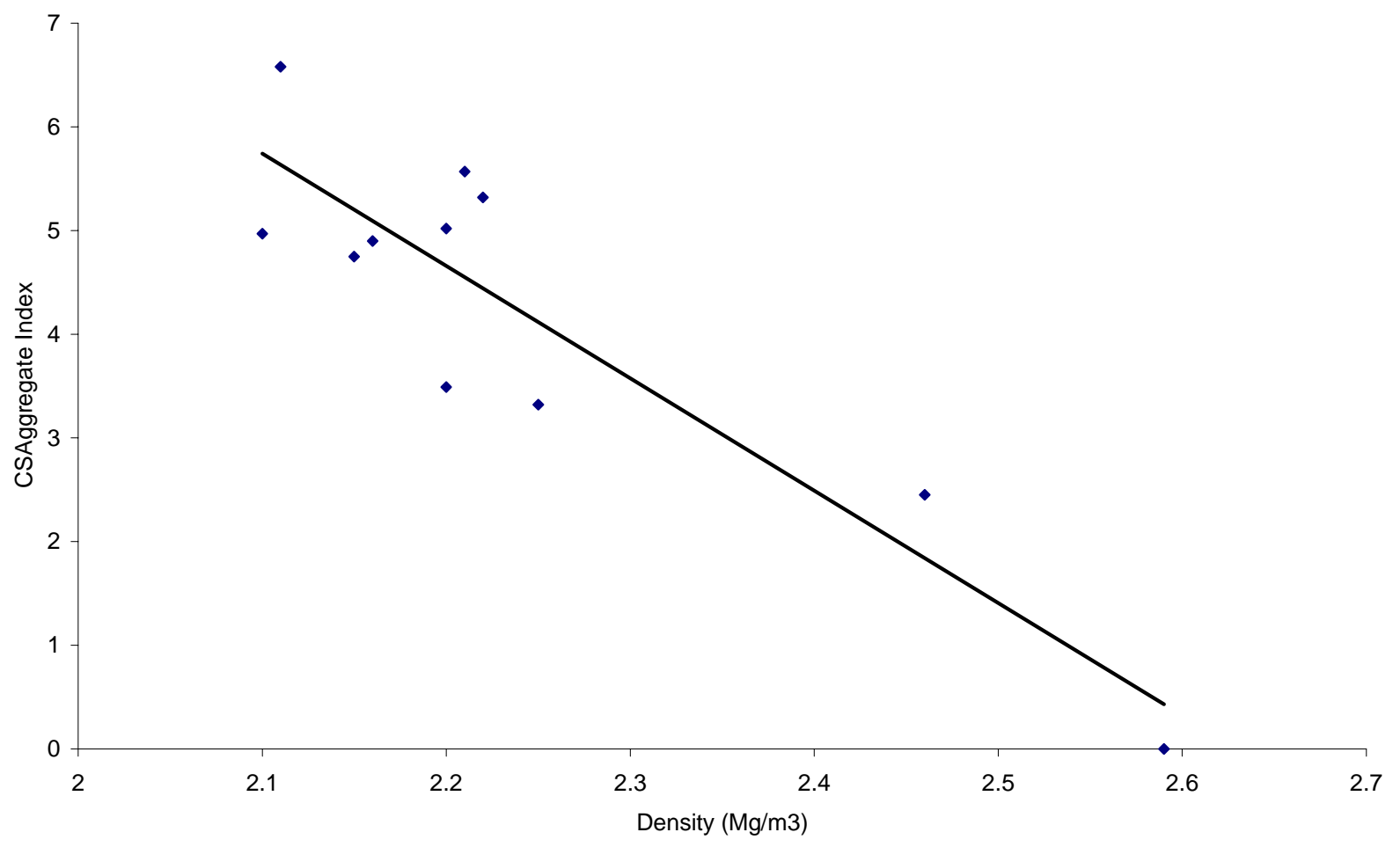

Figure 16: Relation of CSAggregate Index and Density for 10mm Aggregate 


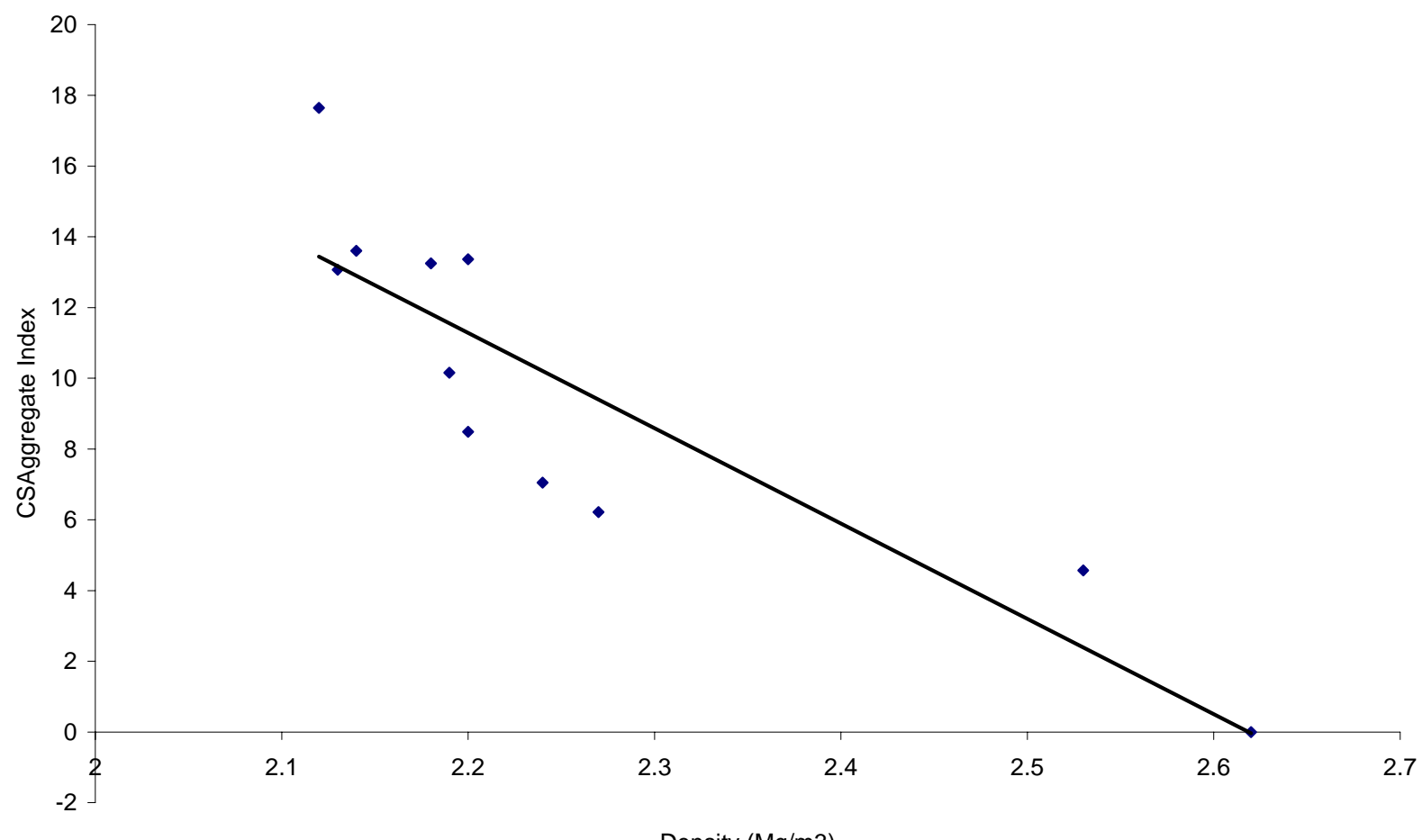

Density (Mg/m3)

Figure 17: Relation of CSAggregate Index and Density for 20mm Aggregate 